SUDRÉ, C.P.; RODRIGUES, R.; RIVA, E.M.; KARASAWA, M.; AMARAL JÚNIOR, A.T. Divergência genética entre acessos de pimenta e pimentão utilizando técnicas multivariadas. Horticultura Brasileira, Brasília, v.23, n.1, p.22-27, jan.-mar. 2005.

\title{
Divergência genética entre acessos de pimenta e pimentão utilizando técnicas multivariadas
}

\author{
Cláudia P. Sudré; Rosana Rodrigues; Elaine M. Riva; Mina Karasawa; Antônio T. do Amaral Júnior \\ UENF/CCTA, Lab. Melh. Genético Vegetal, Av. Alberto Lamego, 2000, Parque Califórnia, 28013-600 Campos dos Goytacazes-RJ; E- \\ mail: cpombo@uenf.br
}

\section{RESUMO}

Técnicas multivariadas foram utilizadas para avaliar a divergência genética entre 56 acessos da coleção de germoplasma de Capsicum spp. da UENF. Foram utilizados onze descritores quantitativos propostos pelo International Plant Genetic Resources Institute, em um experimento conduzido em condições de campo, em Campos dos Goytacazes (RJ), no delineamento de blocos ao acaso com três repetições e 10 plantas por parcela. A distância generalizada de Mahalanobis $\left(\mathrm{D}^{2}\right)$ foi utilizada como medida de dissimilaridade. Foram aplicadas variáveis canônicas, método hierárquico do vizinho mais próximo, método de otimização de Tocher e projeção das distâncias no plano. As variáveis avaliadas foram comprimento e diâmetro do fruto, número de sementes por fruto, peso médio do fruto, altura de planta, diâmetro da copa, peso de 1000 sementes, dias para florescimento, dias para frutificação, número de frutos por planta e peso de frutos por planta. Houve diferença significativa entre os acessos para todos os descritores avaliados. Observou-se concordância entre todas as técnicas multivariadas utilizadas e foi possível separar os acessos em oito grupos distintos, indicando a existência de variabilidade genética entre os acessos. A maior distância generalizada de Mahalanobis foi 266,42. Observou-se que acessos têm potencial para serem utilizados como genitores em cruzamentos para obtenção de progênies com alta heterose. Pela análise das variáveis canônicas observou-se que os cruzamentos com maior potencial heterótico seriam 56x43, 34x08 e 59x41.

Palavras-chave: Capsicum spp., germoplasma, variáveis canônicas, método de Tocher, projeção das distâncias no plano, recursos genéticos.

\begin{abstract}
Genetic divergence between 'chili' and sweet pepper accessions using multivariate techniques

Multivariate techniques were used to evaluated the genetic divergence among 56 accessions of 'chili' and sweet pepper from the germplasm collection of Universidade Estadual do Norte Fluminense. Eleven quantitative descriptors proposed by International Plant Genetic Resources Institute were utilized in a field experiment carried out in Campos dos Goytacazes, Rio de Janeiro State, Brazil, in a randomized block design with three replications and ten plants per plot. Generalized Mahalanobis distance $\left(\mathrm{D}^{2}\right)$ was used as dissimilarity measure. Canonical variated analysis, cluster analysis using Tocher's optimization method and distances in the plan were applied. The variables: fruit length, fruit diameter, number of seeds per fruit, fruit average weight, plant height, plant canopy width, 1000-seed weight, days to flowering, days to fruiting, fruit number per plant and fruit weight per plant were evaluated. There was significant difference among accessions for all descriptors evaluated. General agreement among all multivariate techniques used in the work was observed and it was possible to separate the accessions in eight distinct groups, indicating that there is genetic variability for the evaluated traits. The highest generalized distance of Mahalanobis was 266.42. Accessions have the potential to be used as parents in artificial crosses to obtain progenies with higher heterosis. Through Canonical variable analysis we observed that crosses with the greatest heterotic potential had been $56 \times 43 ; 34 \times 08$, and $59 \times 41$
\end{abstract}

Keywords: Capsicum spp., germplasm, canonical variables, Tocher's method, distance in a plan, genetic resources.

\section{(Recebido para publicação em 14 de outubro de 2003 e aceito em 2 de setembro de 2004)}

$\mathrm{E}$ studos de divergência genética são importantes para o conhecimento da variabilidade genética das populações e possibilitam o monitoramento de bancos de germoplasmas (Cruz e Carneiro, 2003), pois geram informações úteis para preservação e uso dos acessos (Toquica et al., 2003). Esses estudos auxiliam a identificação de possíveis duplicatas, e fornecem parâmetros para escolha de progenitores, que ao serem cruzados, possibilitam maior efeito heterótico na progênie, isto é, aumentam as chances de obtenção de genótipos superiores em gerações segregantes. Tais estimativas são de grande utilidade nos programas de melhoramento (Cruz e Carneiro, 2003), e também na escolha de progenitores para mapeamento de genes (Paran et al., 1998).

Marshall (1989), estimou que 0,5\% dos acessos de um banco devem ser requisitados por ano, e considerou que este seria o uso mínimo desejável. Porém, isto dificilmente acontece, e segundo Li et al. (1998), os fatores que dificultam o uso do banco de germoplasma são a não disponibilidade dos acessos aos melhoristas, a falta de conhecimento sobre os acessos conservados e o não conhecimento dos curadores sobre os programas realizados pelos melhoristas. Hammer (2003), afir- ma que um banco de germoplasma não pode ser um museu, devendo-se estimular a avaliação dos acessos por meio de análises genéticas.

Para determinar quão distante geneticamente uma população ou genótipo é de outra são utilizados métodos biométricos, onde se quantifica ou se estima a heterose, que são analisados pela estatística multivariada permitindo unificar múltiplas informações de um conjunto de caracteres. Vários métodos podem ser utilizados, dentre eles estão a análise por componentes principais, variáveis canônicas e métodos aglomerativos. A escolha do método 
depende da precisão desejada pelo pesquisador, da facilidade da análise e da forma como os dados são obtidos (Cruz e Regazzi, 2001).

$\mathrm{O}$ uso da análise multivariada em estudos sobre divergência genética tem sido assunto de extensas pesquisas em várias culturas como Capsicum (Oliveira et al. 1999; Marita et al., 2000; Toquica et al., 2003; Zewdie et al., 2004;); feijão-vagem (Peixoto et al., 2002); melão rendilhado (Rizzo e Braz, 2002); abóbora (Ramos et al., 2000); moranga (Amaral Júnior, 1999), e alho (Sobrinho et al., 1999).

Pickersgill (1997) estudando a importância dos recursos genéticos no melhoramento de Capsicum spp., concluiu que a diversidade disponível dentro das espécies domesticadas tem sido pouco explorada e ainda não foi esgotada. Garcia (2002), relata que, no México, a enorme diversidade genética disponível em Capsicum annuиm tem facilitado o desenvolvimento de novas variedades e híbridos. Esse autor registra ainda que diversos melhoristas têm observado que, assim como em outras culturas, o nível de heterose em pimentão está diretamente relacionado com a distância genética entre os progenitores, o que torna importante o uso de técnicas adequadas para a estimativa da divergência genética.

O Brasil é um importante centro secundário de espécies domesticadas do gênero Capsicum, podendo-se observar considerável diversidade em C. annuum var. annuum, C. baccatum var. pendulum, C. frutescens e C. chinense. Esta última tem sua área de maior diversidade na Bacia Amazônica, podendo ser considerada como a mais brasileira entre as espécies domesticadas (Reifschneider, 2000). Bianchetti (1996) concluiu que há um centro de diversidade no Rio de Janeiro (Brasil), sendo composto pelo maior número de táxons silvestres do gênero Capsicum.

Este trabalho objetivou caracterizar 56 acessos da Coleção de Capsicum spp. da UENF, com base em 11 descritores essenciais propostos pelo IPGRI (1995), avaliar a divergência genética entre os acessos utilizando diferentes técnicas de análise multivariada, e predizer os cruzamentos com maior potencial heterótico que poderão ser utilizados em programas de melhoramento e em mapeamento de genes.

\section{MATERIAL E MÉTODOS}

Cinqüenta e seis acessos da Coleção de Germoplasma de Capsicum da UENF, provenientes de diversas regiões geográficas, foram utilizados neste estudo. O experimento foi conduzido na Unidade de Apoio à Pesquisa da UENF, utilizando o delineamento experimental em blocos ao acaso, com 56 tratamentos (acessos), três repetições e 10 plantas por parcela, no período de novembro de 2001 a julho de 2002. O espaçamento utilizado foi de $1,0 \mathrm{~m}$ entre linhas e 0,5 m entre plantas. Os tratos culturais seguiram as recomendações feitas por Filgueira (2000).

Para a caracterização morfoagronômica foram considerados os descritores essenciais, altamente discriminantes e outros que foram considerados pertinentes, propostos pelo IPGRI (1995): altura da planta (AP) e diâmetro da copa (DC): ambos mensurados com trena metálica em sua maior distância, em cm, quando 50\% das plantas da parcela apresentaram frutos maduros; dias para florescimento (DPFLOR): número de dias do transplantio até 50\% das plantas da parcela apresentarem pelo menos uma flor aberta; dias para a frutificação (DPFRUT): número de dias do transplantio até $50 \%$ das plantas da parcela apresentarem frutos maduros na primeira e/ou segunda bifurcação; comprimento do fruto $(\mathrm{CF})$ e diâmetro do fruto (DF), ambos mensurados na maior distância, em cm, quando o fruto estava maduro, com paquímetro digital, por parcela foram mensurados 100 frutos; peso médio do fruto (PMF), obtido utilizando-se a razão entre o peso total de frutos por planta (g) e o número de frutos por planta; peso de 1000 sementes (PMS), contou-se e pesou-se em balança analítica, aproximadamente 250 sementes, posteriormente calculou-se o peso equivalente para 1000 sementes em gramas; e número de sementes por fruto (NSF), utilizando-se a média de 100 frutos por parcela. Além da caracterização, dois descritores de avaliação, re- comendados pelo IPGRI (1995) foram considerados; número de frutos por planta (NFP), somatório do número de frutos obtidos em todas as colheitas realizadas, e peso de frutos por planta (PFP), somatório do peso de todos os frutos colhidos.

As análises estatísticas, tais como: análise de variância, teste para comparação de médias Scott-Knott, cálculo da distância de Mahalanobis $\left(\mathrm{D}^{2}\right)$, variáveis canônicas, projeção das distâncias no plano, método do vizinho mais próximo e método de otimização de Tocher, foram realizadas utilizando-se o programa computacional GENES (Cruz, 2001).

\section{RESULTADOS E DISCUSSÃO}

$\mathrm{Na}$ análise de variância univariada dos 11 descritores analisados nos 56 acessos de Capsicum spp. pôde-se observar efeito significativo $(\mathrm{P}<0.01)$ para todos os caracteres, implicando na existência de variabilidade genética entre os acessos estudados. Não houve multicolinearidade entre os caracteres avaliados, permitindo a aplicação das técnicas de análise multivariada citadas no material e métodos.

Para formação do dendrograma pelo método do vizinho mais próximo considerou-se a maior distância, 266,42 (obtida pela $\mathrm{D}^{2}$ ) como $100 \%$ de distância. No eixo $\mathrm{X}$ foram representadas as porcentagens das distâncias entre os acessos e no eixo $\mathrm{Y}$ foram representados os 56 acessos (Figura 1). A ocorrência de mudanças abruptas, e o conhecimento prévio dos acessos, foram utilizados para a formação de grupos no dendrograma. Este agrupamento é considerado subjetivo (Cruz e Regazzi, 2001). Daí a importância de aplicar-se mais de um método de agrupamento, visando coerência dos resultados apresentados.

O corte próximo a $30 \%$ de distância, resultou na formação de sete grupos, que foram: grupo I (acesso 41); grupo II (acesso 43); grupo III (acessos 7, 9 e 8); grupo IV (acessos 44; 13; 42; 27 ; 46 e 45); grupo V (acesso 56); grupo VI (acesso 28$)$ e o grupo VII $(02 ; 53 ; 38$; $52 ; 10 ; 23 ; 22 ; 34 ; 55 ; 49 ; 24 ; 35 ; 19$; $14 ; 25 ; 15 ; 30 ; 06 ; 20 ; 18 ; 11 ; 04 ; 60$; $50 ; 29 ; 47 ; 16 ; 59 ; 39 ; 36 ; 12 ; 17 ; 37$; 


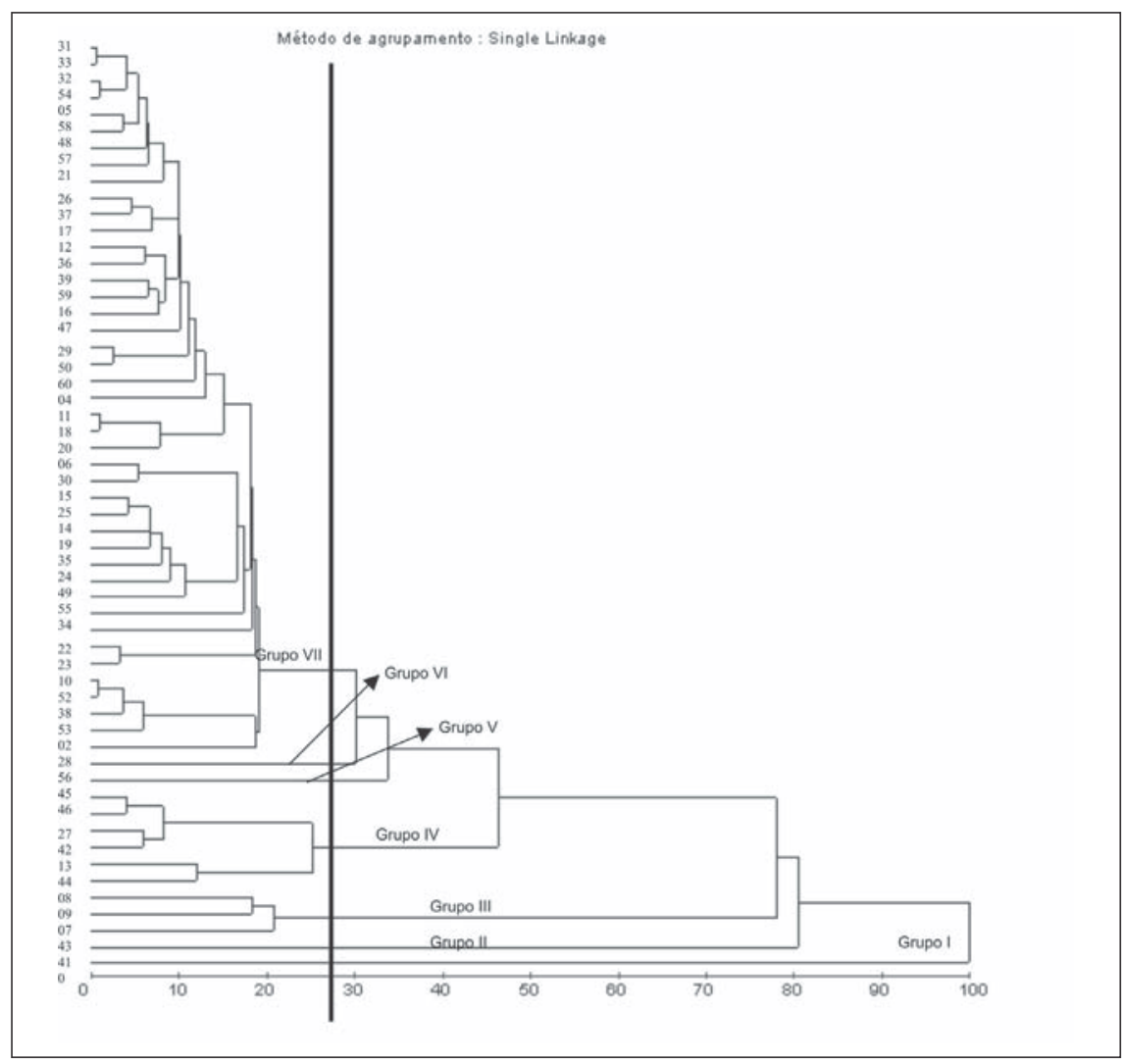

Figura 01. Dendrograma de dissimilaridades genéticas entre 56 acessos de Capsicum spp, obtido pelo método do vizinho mais próximo, com base em 11 caracteres, utilizando-se a distância generalizada de Mahalanobis. Campos dos Goytacazes, UENF, 2002.

$26 ; 21 ; 57 ; 48 ; 58 ; 05 ; 54 ; 32 ; 33$ e 31$)$

Os caracteres que mais contribuíram para divergência genética pelo método Singh (1981) foram: CF (32\%), DF (32\%), NSF (13\%) e PMF (12\%), totalizando 89\% (Sudré et al., 2003), assim a discussão da formação dos grupos teve como base esses quatro caracteres (Tabela 1).

No grupo I, formado pela espécie $C$. annuиm var. annuиm, foram observados a maior média para CF $(16,55 \mathrm{~cm})$, e altos valores para DF $(4,59 \mathrm{~cm}), \mathrm{NSF}$ (204 sementes) e PMF (48,28 g).

O grupo II representado apenas pelo acesso 43 recebeu a mesma letra do acesso 41 pelo teste de médias ScottKnott, onde foi observada a segunda maior média para CF $(16,41 \mathrm{~cm})$. Porém, para o caráter $\mathrm{DF}$, foi observado valor médio $(2,65 \mathrm{~cm})$ inferior ao acesso 41 , com diferença de quase $100 \%$. A média para NSF foi de 148 sementes e PMF de 25,54 g. Na caracterização qualitativa apenas número de lóculos foi diferente, sendo verificado três lóculos para o acesso 41 e dois lóculos para o acesso 43.

O grupo III foi composto pelos acessos 07 (pimentão 'Apolo'), 09 (pimentão 'Ikeda') e 08 (pimentão 'Hércules'), todos cultivares comerciais de $C$. annuиm var. annuиm. $\mathrm{O} \mathrm{CF}$ variou de 8,85 a $10,96 \mathrm{~cm}$, e o DF entre 5,10 a $5,58 \mathrm{~cm}$, sendo os três maiores diâmetros dos 56 acessos caracterizados. O NSF verificado nos acessos 08 e 09 foi respectivamente, 210 e 214 sementes, sendo estes os maiores valores, e 167 sementes para o acesso 07 . Foram verificados os maiores PMF (56,29 e 58,98 g) nos acessos 07 e 08 e o acesso 09 com 43,6 g.

$\mathrm{O}$ grupo IV foi formado pelo acesso 13 de C. baccatum var. pendulum (domesticado), com CF igual a $10,63 \mathrm{~cm}$, DF de 2,90 cm, média de $173 \mathrm{NSF}$ e PMF de 18,12 g. Dentre as pimentas conhecidas vulgarmente como "dedode-moça”, foi a de maior CF e PMF. Os demais acessos do grupo IV, pertencem à mesma espécie e variedade, $C$. annuum var. annuиm (44; 42; 27; 46 e 45), e o acesso 27 , pimenta proveniente do Mé- xico, obteve o menor comprimento $(7,78 \mathrm{~cm})$ e demais acessos variaram entre 8,85 a 11,56 cm. Em DF variaram de 3,07 a 3,61 cm e com altos valores para NSF (114 a 174 sementes) (Tabela 1).

No grupo $\mathrm{V}$ formado pelo acesso 56 (C. baccatum var. baccatum), observouse baixo CF $(3,27 \mathrm{~cm})$, mas com DF $(5,06 \mathrm{~cm}), 104 \mathrm{NSF}$ e PMF de 8,64 g (Tabela 1).

Para o grupo VI (acesso 28), C.annuum var. annuum, verificou-se fruto muito comprido $(9,71 \mathrm{~cm})$ e com pequeno DF $(1,19 \mathrm{~cm})$, similar a um fruto de "malagueta" (C. frutescens), porém três vezes maior. O NSF foi 55 e o PMF 8,32 g (Tabela 1).

O grupo VII foi composto por 43 acessos. Caracterizou-se por acessos com $\mathrm{CF}$ inferior a $7,63 \mathrm{~cm}$. Todos os acessos de C. frutescens ("malaguetas" e "tabasco"), C. chinense ("pimentas de cheiro" e "de bode") e C. annuum var. glabriusculum ("olhos-de-passarinho") encontraram-se neste grupo. No dendrograma da Figura 1 pode-se observar que o grupo VII foi subdividido em dois grandes grupos, o VIIa pelos acessos $02 ; 53 ; 38 ; 52 ; 10 ; 23 ; 22 ; 34$; $55 ; 49 ; 24 ; 35 ; 19 ; 14 ; 25 ; 15 ; 30$ e 06 e o VIIb pelos acessos 20; 18; 11; 04; 60; $50 ; 29 ; 47 ; 16 ; 59 ; 39 ; 36 ; 12 ; 17 ; 37$; 26; $21 ; 57 ; 48 ; 58 ; 05 ; 54 ; 32 ; 33$ e 31 .

No grupo VIIa encontram-se os acessos restantes de $C$. annuum var. annuum, todos pungentes. Próximos a estes, pode-se observar que os dois acessos de C. annuum var. glabriusculum também ficaram próximos no dendrograma, demonstrando grande similaridade. Os acessos de $C$. chinense estão em ambos subgrupos, e os dois acessos referentes às pimentas "saco de bode" (acessos 22 e 23) ficaram muito próximos (Figura 1).

No grupo VIIb pode-se observar todos os acessos de $C$. frutescens. O acesso 60 , conhecido como "tabasco", com formato ligeiramente diferente das "malaguetas", similar a um cilindro, ficou um pouco afastado dos demais, com CF de 3,05 cm, DF de 0,91 cm, NSF igual a 22 sementes e PMF de 0,68 g, e cor amarelo laranja pálido, já as malaguetas foram vermelhas. Os acessos $16 ; 59 ; 39 ; 36$ e 12, conhecidos vul- 
Divergência genética entre acessos de pimenta e pimentão utilizando técnicas multivariadas

Tabela 1. Resumo das médias ${ }^{1}$ aritméticas de 56 acessos de Capsicum spp., com os quatro descritores de maior relevância. Campos dos Goytacazes, UENF, 2002.

\begin{tabular}{|c|c|c|c|c|c|c|c|c|c|}
\hline Acesso & $\mathrm{CF}^{2 l}$ & DF & NSF & PMF & Acesso & $\mathrm{CF}^{2 /}$ & DF & NSF & PMF \\
\hline 2 & $4,47 \mathrm{~g}$ & $1,56 \mathrm{i}$ & $100 \mathrm{e}$ & $2,83 \mathrm{~g}$ & 31 & $1,70 \mathrm{j}$ & $1,96 \mathrm{~h}$ & $34 \mathrm{~h}$ & $1,96 \mathrm{~g}$ \\
\hline 4 & $2,55 \mathrm{i}$ & $3,15 \mathrm{f}$ & $68 \mathrm{f}$ & $5,88 \mathrm{f}$ & 32 & $1,27 j$ & $1,52 \mathrm{i}$ & $29 \mathrm{~h}$ & $1,06 \mathrm{~g}$ \\
\hline 5 & $1,89 \mathrm{j}$ & $1,33 i$ & $33 \mathrm{~h}$ & $0,98 \mathrm{~g}$ & 33 & $1,48 j$ & $2,04 \mathrm{~h}$ & $38 \mathrm{~g}$ & $2,02 \mathrm{~g}$ \\
\hline 6 & $6,72 \mathrm{e}$ & $2,90 \mathrm{f}$ & $52 \mathrm{~g}$ & $6,30 \mathrm{f}$ & 34 & $1,48 \mathrm{j}$ & 0,99 j & $15 \mathrm{~h}$ & $0,45 \mathrm{~g}$ \\
\hline 7 & $10,96 \mathrm{~b}$ & $5,33 a$ & $167 b$ & 56,29 a & 35 & $7,18 \mathrm{e}$ & $2,21 \mathrm{~h}$ & $107 \mathrm{e}$ & $6,21 \mathrm{f}$ \\
\hline 8 & $9,52 \mathrm{c}$ & 5,58 a & $210 a$ & 58,98 a & 36 & $2,97 \mathrm{i}$ & $0,78 \mathrm{k}$ & $28 \mathrm{~h}$ & $0,50 \mathrm{~g}$ \\
\hline 9 & $8,85 \mathrm{c}$ & $5,10 \mathrm{~b}$ & $214 a$ & $43,60 \mathrm{~b}$ & 37 & $3,67 \mathrm{~h}$ & $2,29 \mathrm{~h}$ & $48 \mathrm{~g}$ & $4,87 \mathrm{~g}$ \\
\hline 10 & $2,69 \mathrm{i}$ & $1,58 \mathrm{i}$ & $65 \mathrm{f}$ & $2,03 \mathrm{~g}$ & 38 & $2,54 \mathrm{i}$ & $1,29 \mathrm{i}$ & $43 \mathrm{~g}$ & $1,19 \mathrm{~g}$ \\
\hline 11 & $3,86 \mathrm{~h}$ & $4,04 d$ & $63 \mathrm{f}$ & $8,97 \mathrm{f}$ & 39 & $2,90 \mathrm{i}$ & $0,97 \mathrm{j}$ & $39 \mathrm{~g}$ & $1,02 \mathrm{~g}$ \\
\hline 12 & $3,22 \mathrm{~h}$ & $1,19 \mathrm{j}$ & $44 \mathrm{~g}$ & $1,04 \mathrm{~g}$ & 41 & $16,55 \mathrm{a}$ & $4,59 \mathrm{c}$ & 204 a & $48,28 \mathrm{~b}$ \\
\hline 13 & $10,63 \mathrm{~b}$ & $2,90 \mathrm{f}$ & $173 b$ & $18,12 \mathrm{e}$ & 42 & $8,85 \mathrm{c}$ & $3,07 f$ & $140 \mathrm{c}$ & $23,00 \mathrm{~d}$ \\
\hline 14 & $5,92 \mathrm{f}$ & $1,59 \mathrm{i}$ & $40 \mathrm{~g}$ & $3,11 \mathrm{~g}$ & 43 & $16,41 \mathrm{a}$ & $2,65 \mathrm{~g}$ & $148 \mathrm{c}$ & $25,54 \mathrm{c}$ \\
\hline 15 & 7,19 e & $1,96 \mathrm{~h}$ & $63 \mathrm{f}$ & $4,34 \mathrm{~g}$ & 44 & $11,56 \mathrm{~b}$ & $3,15 f$ & $174 \mathrm{~b}$ & $21,77 d$ \\
\hline 16 & $3,01 \mathrm{i}$ & $1,45 \mathrm{i}$ & $28 \mathrm{~h}$ & $0,45 \mathrm{~g}$ & 45 & $9,16 \mathrm{c}$ & $3,61 \mathrm{e}$ & $148 \mathrm{c}$ & $29,73 \mathrm{c}$ \\
\hline 17 & $3,33 \mathrm{~h}$ & $2,26 \mathrm{~h}$ & $42 \mathrm{~g}$ & $3,44 \mathrm{~g}$ & 46 & $9,12 \mathrm{c}$ & $3,54 \mathrm{e}$ & $164 \mathrm{~b}$ & $27,42 \mathrm{c}$ \\
\hline 18 & $3,59 \mathrm{~h}$ & $4,02 \mathrm{~d}$ & $68 \mathrm{f}$ & $8,42 \mathrm{f}$ & 47 & $1,66 \mathrm{j}$ & $1,10 \mathrm{j}$ & $20 \mathrm{~h}$ & $0,70 \mathrm{~g}$ \\
\hline 19 & 7,19 e & $2,03 \mathrm{~h}$ & $69 \mathrm{f}$ & $6,01 \mathrm{f}$ & 48 & $1,78 \mathrm{j}$ & $2,00 \mathrm{~h}$ & $49 \mathrm{~g}$ & $1,98 \mathrm{~g}$ \\
\hline 20 & $3,66 \mathrm{~h}$ & $4,11 d$ & $78 \mathrm{f}$ & $9,03 \mathrm{f}$ & 49 & $6,95 \mathrm{e}$ & $2,02 \mathrm{~h}$ & $43 \mathrm{~g}$ & $7,20 \mathrm{f}$ \\
\hline 21 & $2,38 \mathrm{i}$ & $2,67 \mathrm{~g}$ & $45 \mathrm{~g}$ & $3,34 \mathrm{~g}$ & 50 & $2,46 \mathrm{i}$ & $2,40 \mathrm{~g}$ & $45 \mathrm{~g}$ & $3,65 \mathrm{~g}$ \\
\hline 22 & $5,07 \mathrm{~g}$ & $4,23 d$ & $73 \mathrm{f}$ & $11,92 \mathrm{e}$ & 52 & $2,54 \mathrm{i}$ & $1,55 \mathrm{i}$ & $66 \mathrm{f}$ & $1,59 \mathrm{~g}$ \\
\hline 23 & $5,14 \mathrm{~g}$ & $4,13 d$ & $75 \mathrm{f}$ & $13,26 \mathrm{e}$ & 53 & $1,56 j$ & $0,86 \mathrm{k}$ & $30 \mathrm{~h}$ & $0,52 \mathrm{~g}$ \\
\hline 24 & $4,71 \mathrm{~g}$ & $1,38 \mathrm{i}$ & $39 \mathrm{~g}$ & $2,07 \mathrm{~g}$ & 54 & $1,30 \mathrm{j}$ & $1,48 \mathrm{i}$ & $39 \mathrm{~g}$ & $1,05 \mathrm{~g}$ \\
\hline 25 & $8,39 \mathrm{~d}$ & $2,05 \mathrm{~h}$ & $66 \mathrm{f}$ & $7,02 \mathrm{f}$ & 55 & $6,97 \mathrm{e}$ & $1,69 \mathrm{i}$ & $73 \mathrm{f}$ & $7,98 \mathrm{f}$ \\
\hline 26 & $4,35 \mathrm{~g}$ & $2,16 \mathrm{~h}$ & $49 \mathrm{~g}$ & $3,85 \mathrm{~g}$ & 56 & $3,27 \mathrm{~h}$ & $5,06 \mathrm{~b}$ & $104 \mathrm{e}$ & $8,64 \mathrm{f}$ \\
\hline 27 & $7,78 \mathrm{~d}$ & $3,13 \mathrm{f}$ & $114 \mathrm{~d}$ & $21,48 d$ & 57 & $2,39 \mathrm{i}$ & $1,62 \mathrm{i}$ & $49 \mathrm{~g}$ & $1,65 \mathrm{~g}$ \\
\hline 28 & $9,71 \mathrm{c}$ & $1,19 \mathrm{j}$ & $66 \mathrm{f}$ & $2,53 \mathrm{~g}$ & 58 & $1,16 j$ & $1,44 \mathrm{i}$ & $46 \mathrm{~g}$ & $0,96 \mathrm{~g}$ \\
\hline 29 & $2,43 i$ & $2,40 \mathrm{~g}$ & $49 \mathrm{~g}$ & $3,31 \mathrm{~g}$ & 59 & $2,47 \mathrm{i}$ & $0,62 \mathrm{k}$ & $20 \mathrm{~h}$ & $0,35 \mathrm{~g}$ \\
\hline 30 & $7,63 \mathrm{~d}$ & $3,05 \mathrm{f}$ & $55 \mathrm{~g}$ & $8,32 \mathrm{f}$ & 60 & $3,05 \mathrm{i}$ & $0,90 \mathrm{k}$ & $22 \mathrm{~h}$ & $0,68 \mathrm{~g}$ \\
\hline
\end{tabular}

${ }^{1 / M e ́ d i a s ~ s e g u i d a s ~ p e l a ~ m e s m a ~ l e t r a, ~ n a ~ m e s m a ~ c o l u n a, ~ p e r t e n c e m ~ a ~ u m ~ m e s m o ~ g r u p o, ~ p e l o ~ t e s t e ~ d e ~(S c o t t-K n o t t) ~ a ~ 1 \% ~ d e ~ p r o b a b i l i d a d e ~ d e ~}$ erro. ${ }^{2 /} \mathrm{CF}=$ comprimento do fruto; $\mathrm{DF}=$ diâmetro do fruto; $\mathrm{NSF}=$ número de sementes por fruto; $\mathrm{PMF}=$ peso médio do fruto.

garmente como "malaguetas", ficaram muito próximos no dendrograma, e com CF variando entre 2,47 e $3,22 \mathrm{~cm}$. O acesso 59 com menor DF dentre os 56 acessos analisados $(0,62 \mathrm{~cm})$, e o acesso 16 o maior entre os acessos de $C$. frutescens $(1,44 \mathrm{~cm})$. O NSF variou entre 20 e 44 sementes e para PMF observou-se menor valor para o acesso 59 $(0,35 \mathrm{~g})$ e maior para o acesso $12(1,04$ g). Portanto, são frutos alongados, pequenos e muito leves, porém produzem muitos frutos por planta, sendo o acesso 12 o que mais produziu entre as "malaguetas" (620 frutos), contudo possuem potencial para produzirem muito mais, pois são perenes e tardias, não permitindo assim uma avaliação definitiva quanto a produção desses acessos. Alguns acessos de C. baccatum também foram observados neste grupo, inclusive o acesso 20 que pertence à variedade baccatum, com formato pitanga, não descrito pelo IPGRI (1995), e acessos da variedade pendulum $(04 ; 50 ; 29 ; 17$; 26 e 21), para os acessos 50 e 29, verificou-se a distância genética de $2,57 \%$ (Tabela 1).

Por ser a heterose no gênero Capsicum positiva para a maioria dos caracteres estudados (Braz et al., 1996; Costa et al., 2002) e a análise multivariada possibilitar a predição dessa heterose, alguns cruzamentos serão recomendados a seguir, porém as possibilidades são muitas, desde que se obedeça o princípio de se cruzar acessos mais distantes e melhores para as características desejadas.

Visando a maior produção de pimentão, podem ser recomendados os cruzamentos entre os acessos do grupo III (pimentões comerciais) com o acesso 43 (grupo II), distantes, não pungentes, grandes e com a coloração para fruto imaturo muito próxima, pois os pimentões são comercializados em grande parte na cor verde (frutos imaturos). Outra opção seria cruzar os acessos do grupo III (07; 08 e 09) com o grupo I (acesso 41), com o dobro do diâmetro do acesso 43 e três lóculos por fruto, portanto, com fenótipo mais próximo do pimentão comercial (cônico), porém com o dobro de CF.

Para fins ornamentais, pode-se sugerir o cruzamento entre os acessos de C. annuum var. glabriusculum (38 e 53), com flores roxas, frutos com várias cores e porte baixo, com acessos ornamentais (10 e 52), com mais de seis cores de fruto durante a fase de maturação e com flores brancas e porte baixo. Outro cruzamento seria entre o acesso 56, frutos com formato sino e flores brancas com manchas amarelas, com o acesso 53, que 


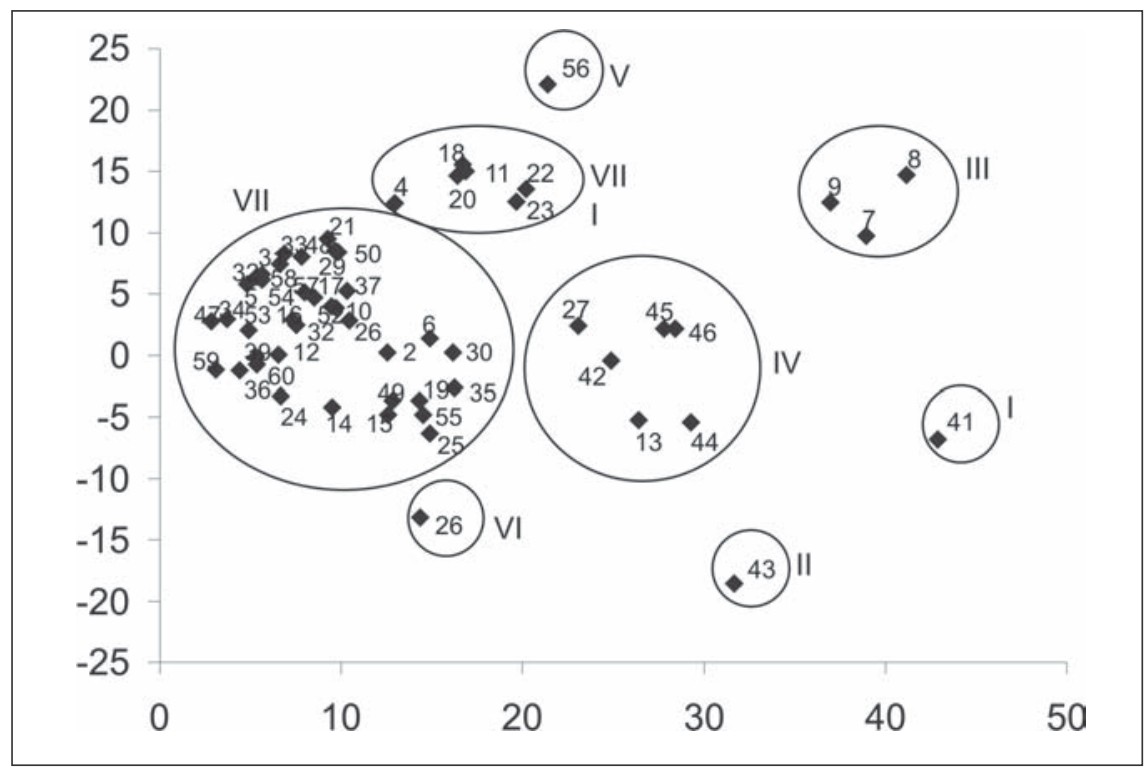

Figura 2. Dispersão gráfica dos escores em relação aos eixos representativos das variáveis canônicas (VC1 e VC2) relativos a 11 caracteres estudados em 56 acessos de Capsicum spp., Campos dos Goytacazes, UENF, 2002.

possui flores roxas, frutos ovais, coloridos e altura média de $24 \mathrm{~cm}$.

No presente trabalho, demonstrouse que é possível estudar a divergência genética com base em caracteres morfoagronômicos, pois os acessos ficaram bem dispersos, formando grupos coerentes, contendo uma ou duas espécies botânicas ou até mesmo variedades botânicas. Foi possível agrupar os diferentes tipos conhecidos, como: "malagueta", "olhos-de-passarinho", "de cheiro", pimentões comerciais, entre outros. Para o melhorista a distinção entre tipos, talvez seja mais interessante que a distinção dos táxons, propriamente dito, devido à facilidade de permuta de genes (Pickergill, 1997).

Ao aplicar o método de Otimização de Tocher foi possível observar a formação de sete grupos distintos, os quais foram muito próximos dos grupos formados pelo método do vizinho mais próximo, sendo os grupos I, II, III, IV, VI idênticos. O grupo $\mathrm{V}$ pelo método do vizinho mais próximo foi composto apenas pelo acesso 56, entretanto no método de Tocher além deste, foram acrescidos os acessos 11; 18; 20; 22 e 23 que pertenciam ao grupo VII.

É interessante observar que dois acessos de $C$. baccatum var. baccatum (20 e 56), ficaram no mesmo grupo, junto com quatro acessos de $C$. chinense, todos apresentando frutos com formato campanulado, que foram duas pimentas do tipo "saco de bode" (acessos 22 e 23) e dois acessos muito semelhantes, porém com o tipo não conhecido (acessos 11 e 18). O grupo VII foi formado por 38 acessos, sendo diferente do grupo VII do método do vizinho mais próximo por excluir os cinco acessos acrescidos no grupo $\mathrm{V}$.

Pelo método da projeção das distâncias no plano pôde-se observar a formação de oito grupos bem distintos, apenas um a mais em relação aos métodos Tocher e vizinho mais próximo. Os grupos formados por este método foram: grupo I, II, III, IV e VI, idênticos aos grupos formados pelo método de Tocher, e os grupos V (acesso 56), VII (acessos 02; 04; 05; 06; 10; 12; 14; 15; $16 ; 17 ; 19 ; 21 ; 24 ; 25 ; 26 ; 29 ; 30 ; 31$; $32 ; 33 ; 34 ; 35 ; 36 ; 37 ; 38 ; 39 ; 47 ; 48$; $49 ; 50 ; 52 ; 53 ; 54 ; 55 ; 57 ; 58 ; 59$ е 60$)$ e VIII (acessos 11; 18; 20; 22 e 23) foram semelhantes. $\mathrm{O}$ grupo $\mathrm{V}$ formado pelo método de Tocher, foi subdividido por este método, em dois grupos, V e VIII, demonstrando ser este método mais preciso, confirmando os dados obtidos de Cruz e Viana (1994).

Pelo método das variáveis canônicas, encontrou-se as estimativas dos autovalores $\left(1_{j}\right)$ associados as variáveis canônicas (VC), de 11 caracteres avaliados em 56 acessos de Capsicum spp. As duas primeiras variáveis explicaram $83,72 \%$ da variação total. Segundo Cruz e Regazzi (2001), quando as duas primeiras variáveis canônicas explicam acima de $80 \%$ da variação total, sua utilização é satisfatória no estudo da divergência genética por meio de avaliação da dispersão gráfica dos escores em relação às variáveis canônicas $\left(1^{\mathrm{a}} \mathrm{VC} \mathrm{e}\right.$ $2^{\text {a }} \mathrm{VC}$ ), assim, fez-se a dispersão gráfica bidimensional dos dois primeiros escores (Figura 2).

Os grupos formados por meio da dispersão gráfica dos escores diferiram dos grupos formados pela projeção das distâncias no plano apenas pelo acesso 04, que por esse método localizou-se no grupo VIII. Isto não está muito definido no gráfico, podendo o acesso 04 pertencer ao grupo VII, como admitido pelos métodos anteriores ou talvez formar um grupo isolado, dependendo da interpretação. Porém, este acesso (C. baccatum var. pendulum) possui o formato pitanga como o acesso 20 (C. baccatum var. baccatum), sendo os dois únicos acessos com esse formato, demonstrando assim que realmente este formato difere dos demais sugeridos pelo IPGRI (1995), já que comprimento e diâmetro contribuíram $64 \%$ para divergência genética entre os acessos. Por este motivo, o acesso 04 ficou incluído no grupo VIII.

A maior distância no eixo Y pode ser observada entre os acessos 43 e 56, e no eixo $\mathrm{X}$ entre os acessos 34 e 08 e praticamente com a mesma distância os acessos 59 e 41, sendo estas três combinações as de maior potencial heterótico. Quanto ao cruzamento entre os acessos 43 e 56, foi observado nas plantas do primeiro acesso, fruto alongado, com comprimento acima de $16 \mathrm{~cm}$, pertencente à espécie $C$. annuum. Para o acesso 56 verificou-se o formato sino, com comprimento de $3,27 \mathrm{~cm}$, pertencente a variedade $C$. baccatum var. baccatum, sendo portanto silvestre, devendo-se conferir se há formação de sementes híbridas viáveis entre esses acessos. $\mathrm{O}$ acesso 34 é altamente pungente, com frutos muito pequenos $(1,48 \mathrm{~cm}$ de comprimento), de cor branca quando maduros e formato oval. O acesso 08 é o pimentão comercial 'Hércules'. O outro 
cruzamento possível é entre os acessos 59 e 41 , sendo o 59 C. frutescens ("malagueta") com frutos de peso médio de $0,35 \mathrm{~g}$ com o acesso 41 ( $C$. annuum) com peso médio de 48,28 g, demonstrando assim a grande diferença entre esses acessos. Além da distância, é necessário saber se o acesso escolhido possui características desejadas, daí a importância de se fazer a caracterização morfoagronômica, com dados qualitativos e quantitativos.

As técnicas multivariadas aplicadas (método hierárquico do vizinho mais próximo, otimização de Tocher, projeção das distâncias no plano e variáveis canônicas) foram concordantes entre si. Os 56 acessos analisados foram divergentes, possuindo variabilidade genética, permitindo potencial uso desses acessos em programas de melhoramento.

\section{LITERATURA CITADA}

AMARAL JÚNIOR, A.T. Divergência genética entre acessos de moranga do banco de germoplasma de hortaliças da Universidade Federal de Viçosa. Horticultura Brasileira, Brasília, v.17, p.3-6, 1999. Palestra. Suplemento.

BIANCHETTI, L.B. Aspectos morfológicos, ecológicos e biogeográficos de dez táxons de Capsicum (Solanaceae) ocorrentes no Brasil. 1996. 174 F. (Tese Mestrado) - UNB, Brasília. BRAZ, L.T.; AOSHIMA, C.T.; FERREIRA, M.A.J.F. Desenvolvimento e avaliação de híbridos de pimentão (Capsicum annuum L.) I. Características agronômicas. Horticultura Brasileira, v.14, n.1, p.74, 1996.

COSTA, R.A.; RODRIGUES, R.; SUDRÉ, C.P Resistência à mancha bacteriana em genótipos de pimentão. Horticultura Brasileira, Brasília, v.20, n.1, p.86-89, 2002.

CRUZ, C.D. Programa genes (versão Windows): aplicativo computacional em genética e estatistica. Viçosa: UFV, 2001. 648 p.
CRUZ, C.D.; CARNEIRO, P.C.S. Modelos biométricos Aplicados ao Melhoramento Genético. Viçosa: UFV, v.2, 2003. 585 p.

CRUZ, C.D.; VIANA, J.M.S. A methodology of genetic divergence analyses based on sample unit projection on two-dimensional space. Revista Brasileira de Genética, Ribeirão Preto, v.17, n.1, p.69 -73, 1994.

CRUZ, C.D.; REGAZZI, A.J. Modelos biométricos aplicados ao melhoramento genético. 2. ed. rev. Viçosa: UFV, 2001. 390 p.

FILGUEIRA, F.A.R. Novo manual de olericultura: agrotecnologia moderna na produção e comercialização de hortaliças. Viçosa: UFV, 2000. 402 p.

GARCIA, B.F. Estimation of genetic distances among green pepper (Capsicum annuum L.) lines using RAPD markers and its relationship with heterosis. Proceedings of the 16th International Pepper Conference. Tampico, Mexico. 2002. p. 37-40.

HAMMER, K.A. Paradigm shift in the discipline of plant genetic resources. Genetic Resources and Crop Evolution, v.50, p.3-10, 2003.

IPGRI. Descriptores para Capsicum (Capsicum spp). Roma: IPGRI, 1995. 51 p.

LI, Y.; WANG J.; CAO, Y.; GAO, W.; FANG, J.; LOU, $X$. The use of genetic resources in crop improvement: Lessons from China. Genetic Resources and Crop Evolution, v.45, p.181-186, 1998

MARITA, J.M.; RODRIGUEZ, J.M.; NIENHUIS, J. Development of an algorithm identifying maximally diverse core collections. Genetic Resources and Crop Evolution, v.47, p.515-526. 2000.

MARSHALL, D.R. Limitations to the use of germplasm collections. In.: BROWN, A.H.D.; MARSHALL, D.R.; FRANKEL, O.H.; WILLIAMS (Eds.) The use of plant genetic resources. Cambridge: Cambridge University Press, 1989. p.105-120.

OLIVEIRA, V.R.; CASALI, V.W.D.; CRUZ, C.D PEREIRA, P.R.; BRACCINI, A.L. Avaliação da diversidade genética em pimentão através de análise multivariada. Horticultura Brasileira, Brasília, v.17, n.1, 1999.

PARAN, I; AFTERGOOT, E.; SHIFRISS Variation in Capsicum annuum revealed by RAPD and AFLP markers. Euphytica, v.99, p.167-173, 1998.
PEIXOTO, N.; BRAZ, L.T.; BANZATTO, D.A.; MORAES, E.A.; MOREIRA, F.M. Características agronômicas, produtividade, qualidade de vagens e divergência genética em feijão-vagem de crescimento indeterminado. Horticultura Brasileira, Brasília, v.20, n.3, p.447-451, 2002.

PICKERSGILL, B. Genetic resoucers and breeding of Capsicum spp. Euphytica, v.96, p.129133, 1997.

RAMOS, S.S.R.; QUEIRÓZ, M.A.; CASALI, V.W.D.; CRUZ, C.D. Divergência genética em germoplasma de abóbora procedente de diferentes áreas do Nordeste. Horticultura Brasileira, Brasília, v.18, n.3, 2000.

REIFSCHNEIDER, F.J.B. Capsicum: pimentas e pimentões no Brasil. Brasília: Embrapa Comunicação Transferência de Tecnologia, 2000. 113 p. RIZZO, A.A.N.; BRAZ, L.T. Divergência genética entre cinco genótipos de melão rendilhado Horticultura Brasileira, Brasília, v.20, n.2, p.171173, 2000.

SINGH, D. The relative importance of characters affecting genetic divergence. Indian Journal of Genetic and Plant Breeding, v.41, n.2, p.237-245, 1981.

SOBRINHO, J.A.M.; CHARCHAR, J.M.; ARAGÃO, F.A.S. Caracterização morfológica de germoplasma de alho por análises multivariada, componentes principais e variáveis canônicas. Horticultura Brasileira, Brasília, v.17, n.2, p.96101, 1999.

SUDRÉ, C.P. Divergência genética e avaliação da resistência à mancha bacteriana em acessos de Capsicum spp. 2003. 112 f. (Tese mestrado) UENF, Campos dos Goytacazes.

TOQUICA, S.P.; RODRÍGUEZ, F.; MARTINEZ, E.; DUQUE, M.C.; TOHME, J. Molecular characterization by AFLPs of Capsicum germplasm from the Amazon department in Colombia. Genetic Resources and Crop Evolution, v.50, n.6, p.639-647, 2003.

ZEWDIE,Y.; TONG, N.; BOSLAND, P. Establishing a core collection of Capsicum using a cluster analysis with enlightened selection of accessions. Genetic Resources and Crop Evolution, v.51, p.147-151, 2004. 